Article

\title{
Extracellular L-arginine Enhances Relaxations Induced by Opening of Calcium-Activated SKCa Channels in Porcine Retinal Arteriole
}

\author{
Ulf Simonsen ${ }^{1, *}{ }^{\oplus}$, Anna K. Winther ${ }^{1}$, Aida Oliván-Viguera ${ }^{2} \oplus$, Simon Comerma-Steffensen ${ }^{1}(\mathbb{D}$, \\ Ralf Köhler ${ }^{3}$ and Toke Bek ${ }^{4}$ (D) \\ 1 Department of Biomedicine, Pulmonary and Cardiovascular Pharmacology, Aarhus University, \\ Wilhelm Meyers Allé 4, DK-8000 Aarhus C, Denmark; annawinther@chem.au.dk (A.K.W.); \\ simoncomerma@biomed.au.dk (S.C.-S.) \\ 2 BESICoS group, Aragón Institute of Engineering Research, IIS-Aragón, University of Zaragoza, \\ 50009 Zaragoza, Spain; aidaolivanviguera@gmail.com \\ 3 Aragón Agency for Research and Development (ARAID) at IACS and IIS Aragón, 50009 Zaragoza, Spain; \\ kohler@araid.es \\ 4 Department of Ophthalmology, Aarhus University Hospital, DK-8000 Aarhus C, Denmark; \\ toke.bek@mail.tele.dk \\ * Correspondence: us@biomed.au.dk; Tel.: +45-87167685
}

Received: 10 April 2019; Accepted: 23 April 2019; Published: 25 April 2019

check for updates

\begin{abstract}
We investigated whether the substrate for nitric oxide (NO) production, extracellular $\mathrm{L}$-arginine, contributes to relaxations induced by activating small (SKCa) conductance $\mathrm{Ca}^{2+}$-activated potassium channels. In endothelial cells, acetylcholine increased ${ }^{3} \mathrm{H}$-L-arginine uptake, while blocking the SKCa and the intermediate (IKCa) conductance $\mathrm{Ca}^{2+}$-activated potassium channels reduced $\mathrm{L}$-arginine uptake. A blocker of the $\mathrm{y}+$ transporter system, $\mathrm{L}$-lysine also blocked ${ }^{3} \mathrm{H}$-L-arginine uptake. Immunostaining showed co-localization of endothelial NO synthase (eNOS), SKCa3, and the cationic amino acid transporter (CAT-1) protein of the $y+$ transporter system in the endothelium. An opener of SKCa channels, cyclohexyl-[2-(3,5-dimethyl-pyrazol-1-yl)-6-methyl-pyrimidin-4-yl]-amine (CyPPA) induced large currents in endothelial cells, and concentration-dependently relaxed porcine retinal arterioles. In the presence of L-arginine, concentration-response curves for CyPPA were leftward shifted, an effect unaltered in the presence of low sodium, but blocked by L-lysine in the retinal arterioles. Our findings suggest that SKCa channel activity regulates L-arginine uptake through the $y+$ transporter system, and we propose that in vasculature affected by endothelial dysfunction, L-arginine administration requires the targeting of additional mechanisms such as SKCa channels to restore endothelium-dependent vasodilatation.
\end{abstract}

Keywords: NO synthase; calcium-activated potassium channel; cationic amino acid transporter; relaxation; retinal arterioles; porcine

\section{Introduction}

Disturbances in retinal blood flow are involved in the pathophysiology of major sight-threatening diseases, such as age-related macular degeneration, primary open angle glaucoma, and diabetic retinopathy [1-4], and involve endothelial dysfunction and impaired endothelium-dependent vasodilatation [5-7]. Nitric oxide (NO), prostaglandins, and endothelium-dependent hyperpolarization (EDH) mediate endothelium-dependent relaxation [8-10], and activation of $\mathrm{Ca}^{2+}$-activated potassium channels of small (SKCa, subtype SKCa3 a.k.a KCa2.3) and intermediate (IKCa, a.k.a. KCa3.1) conductance are involved in the activation of these signal pathways [11,12]. Prostaglandin-mediated 
endothelium-dependent relaxation is of less significance in retinal arterioles [13-16]. In rats, the EDH pathway is involved in endothelium-dependent relaxation in retinal arteries [17], but this is not the case in retinal arterioles from pigs [13] and man [18]. These findings support that NO is the main mediator of endothelium-dependent relaxation in retinal arterioles [19]. We have previously found that the SKCa channel is involved in the bradykinin-induced NO-mediated relaxation of porcine retinal arterioles $[13,14]$. Concerning the underlying mechanisms, it has been proposed that the activation of endothelial SKCa channels and the resulting membrane hyperpolarization increases the electrochemical driving force for $\mathrm{Ca}^{2+}$ entry and the subsequent activation of $\mathrm{Ca}^{2+}$-dependent NO formation and release [20-22]. Moreover, endothelial cell hyperpolarization may also decrease superoxide formation by decreasing the activity of NAPDH oxidase [23]. However, in intact vascular preparations, activators of SKCa channels, such as 6,7-Dichloro-1H-indole-2,3-dione 3-oxime (NS309) and cyclohexyl-[2-(3,5-dimethyl-pyrazol-1-yl)-6-methyl-pyrimidin-4-yl]-amine (CyPPA), relax porcine retinal arterioles by a mechanism, which to a large degree are independent of changes in endothelial cell $\mathrm{Ca}^{2+}[14]$. These findings suggest that other mechanisms contribute to the relaxations induced by the activation of SKCa channels in porcine retinal arterioles.

Regulation of endothelial L-arginine uptake has been proposed to play a role for endothelial NO release and blood flow regulation in vivo [24]. This is also supported by the observations that L-arginine uptake, rather than the intracellular L-arginine concentration, is important for NO production in endothelial cells [25]. Indeed, in isolated rabbit eyes, administration of L-arginine decreases ocular vascular tone [26], supporting a major role for L-arginine uptake and NO release in endothelium-dependent relaxation in retinal arterioles.

The majority of the L-arginine uptake in endothelial cells occurs by the $\mathrm{Na}^{+}$-independent $\left(\mathrm{y}^{+}\right.$system) cationic amino acid transporter (CAT) $[27,28]$. The L-arginine transport by the $\mathrm{y}^{+}$system appears to depend on the membrane potential, where hyperpolarization increases and depolarization decreases L-arginine uptake $[29,30]$. Based on these findings, we hypothesized that hyperpolarization caused by activating SKCa channels increases L-arginine uptake through the $\mathrm{y}^{+}$transporter system and enhances NO-mediated relaxation.

To address the hypothesis, we performed measurements of ${ }^{3} \mathrm{H}$-L-arginine uptake in the absence and the presence of SKCa and IKCa channel blockers and of the CAT system in isolated rat aortic valve endothelial cells, which served as an in situ endothelial cell preparation avoiding L-arginine uptake in other cell types. We performed immunohistochemistry in porcine retinal arterioles to reveal the localization of endothelial NO synthase (eNOS), SKCa3, and CAT-1 protein. In isolated porcine retinal arterioles, we studied the effect of L-arginine in the absence and the presence of inhibitors of the CAT system on relaxation induced by bradykinin and CyPPA, an activator of SKCa3 channels [31]. Our findings suggest that SKCa channel activity regulates L-arginine uptake through the $\mathrm{y}^{+}$transporter system.

\section{Results}

\subsection{L-arginine Uptake in Rat Valve Endothelial Cells}

To address the role of SKCa and IKCa channels in L-arginine uptake, ${ }^{3} \mathrm{H}$-L-arginine uptake was investigated in aortic valve endothelial cells. Baseline uptake of ${ }^{3} \mathrm{H}-\mathrm{L}$-arginine was $2532 \pm 394 \mathrm{cpm}$ $(n=6)$. This uptake increased to $4458 \pm 726 \mathrm{cpm}(n=6)$ in the presence of $10 \mu \mathrm{M}$ acetylcholine. Uptake was abolished by the combination of SKCa- and IKCa channel blockers, apamin $(0.5 \mu \mathrm{M})$ and ChTX $(0.1 \mu \mathrm{M})(2345 \pm 632 \mathrm{cpm}, n=6)$. In contrast, replacing normal PSS with low $\mathrm{Na}^{+}$-containing PSS to inhibit the Bo, + transporter system had no effect on ${ }^{3} \mathrm{H}$-L-arginine uptake $(3792 \pm 772 \mathrm{cpm})$, whereas L-lysine $(600 \mu \mathrm{M})$ that inhibits L-arginine uptake by the $\mathrm{y}^{+}$transporter system, virtually abolished ${ }^{3} \mathrm{H}$-L-arginine uptake $(151 \pm 23 \mathrm{cpm})$ (Figure 1$)$. 


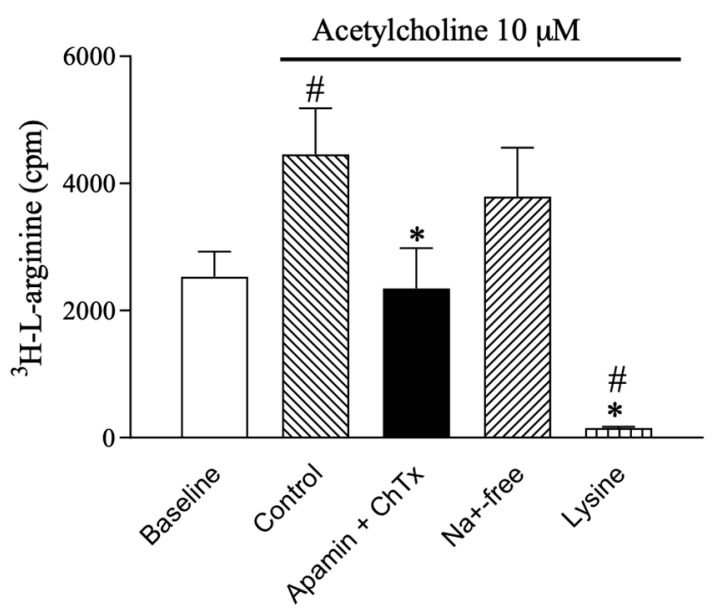

Figure 1. ${ }^{3} \mathrm{H}$-L-arginine uptake in rat aortic valve endothelial cells in the absence and presence of the combination of apamin $(0.5 \mu \mathrm{M})$, a SKCa channel blocker, and charybdotoxin (ChTX, $0.1 \mu \mathrm{M})$, an IKCa channel blocker, and of L-lysine $(600 \mu \mathrm{M})$, both inhibiting L-arginine uptake through the CAT system, and of low $\mathrm{Na}^{+}$-PSS which inhibits L-arginine uptake through the $\mathrm{Na}^{+}$-dependent $(\mathrm{Bo},+) \mathrm{CAT}$ system. Data are means \pm S.E.M. $(n=6)$. One-way ANOVA. $\# p<0.05$ vs. baseline. ${ }^{*} p<0.05$ vs. control.

\subsection{Localization of eNOS, SKCa3 and CAT-1 Protein}

To evaluate the localization of eNOS, SKCa3 and CAT-1 protein in retinal arterioles, the vascular segments were fixed with surrounding retinal tissue, and eNOS, smooth muscle actin, SKCa3, and CAT-1 were immune-labeled (Figure 2).
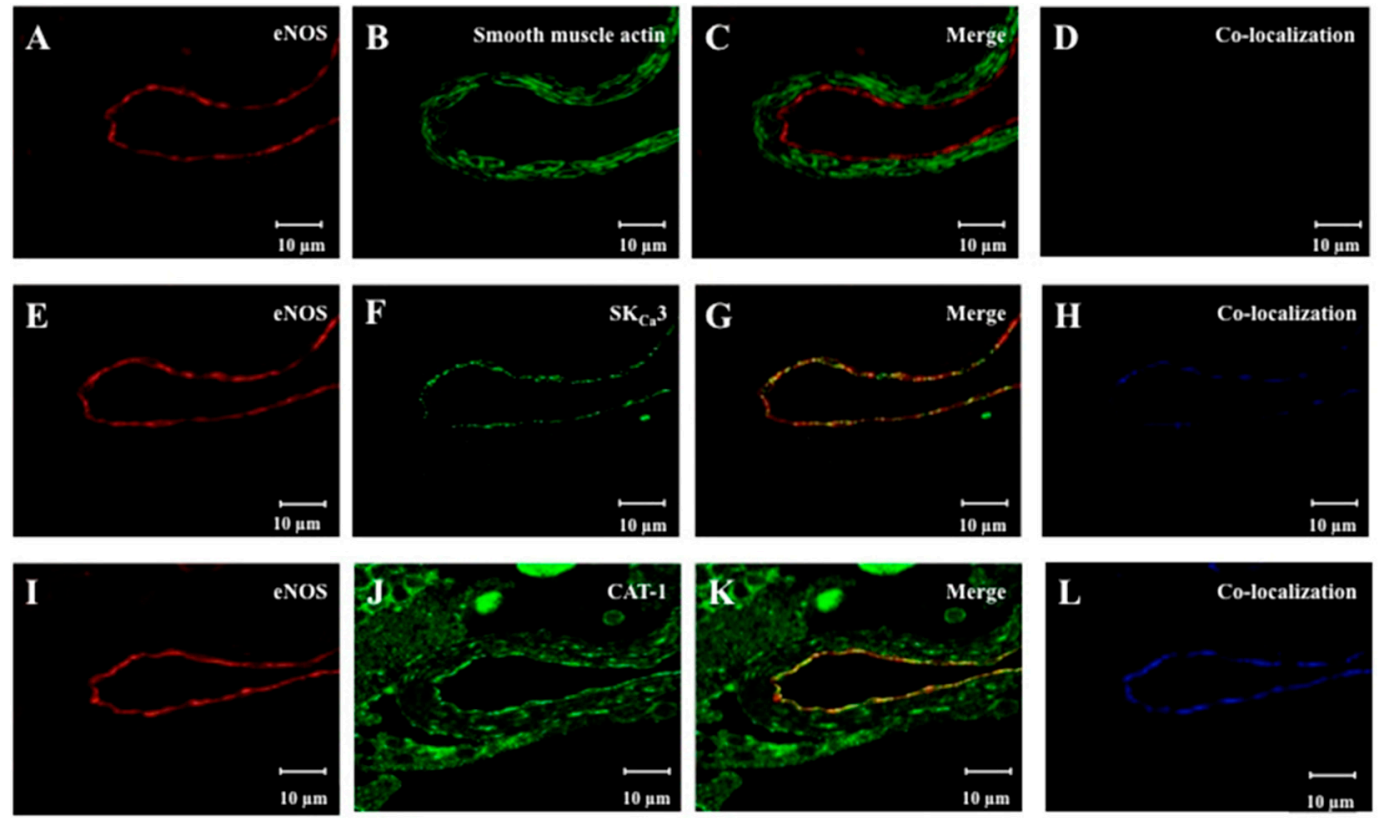

Figure 2. Representative images showing immunoreaction for (A) eNOS, (B) smooth muscle actin, and (C) merged immunoreaction for eNOS and smooth muscle actin, and (D) no co-localization of eNOS and smooth muscle actin. Immunoreaction for (E) eNOS, (F) SKCa3, and (G) merged immunoreaction for eNOS and SKCa3, and (H) co-localization in blue of eNOS and SKCa3. Immunoreaction for (I) eNOS, (J) CAT-1, and (K) merged immunoreaction for eNOS and CAT-1, and (L) co-localization in blue of eNOS and CAT-1.

eNOS and SKCa3 immunoreactions were observed in the vascular endothelium (Figure 2E-G), but not in the vascular smooth muscle layer (Figure 2C). Immunoreactions for smooth muscle actin 
were observed in the vascular smooth muscle layer, but not in the vascular endothelium. Furthermore, immunoreactions for CAT- 1 were found both in the vascular endothelium and the smooth muscle cells (Figure 2J,K). eNOS was found to be co-localized with SKCa3, and CAT-1 in the endothelium (Figure 2H,L).

\subsection{Pharmacological Activation of SKCa Channels in Porcine Arterial Endothelial Cells}

Based on cell lines expressing SKCa channels, CyPPA is considered an activator of the SKCa-subtypes, SKCa2 and SKCa3 [31]. To investigate whether CyPPA activates SKCa currents in primary endothelial cells, we performed patch clamp electrophysiology on porcine arterial endothelial cells (Figure 3).
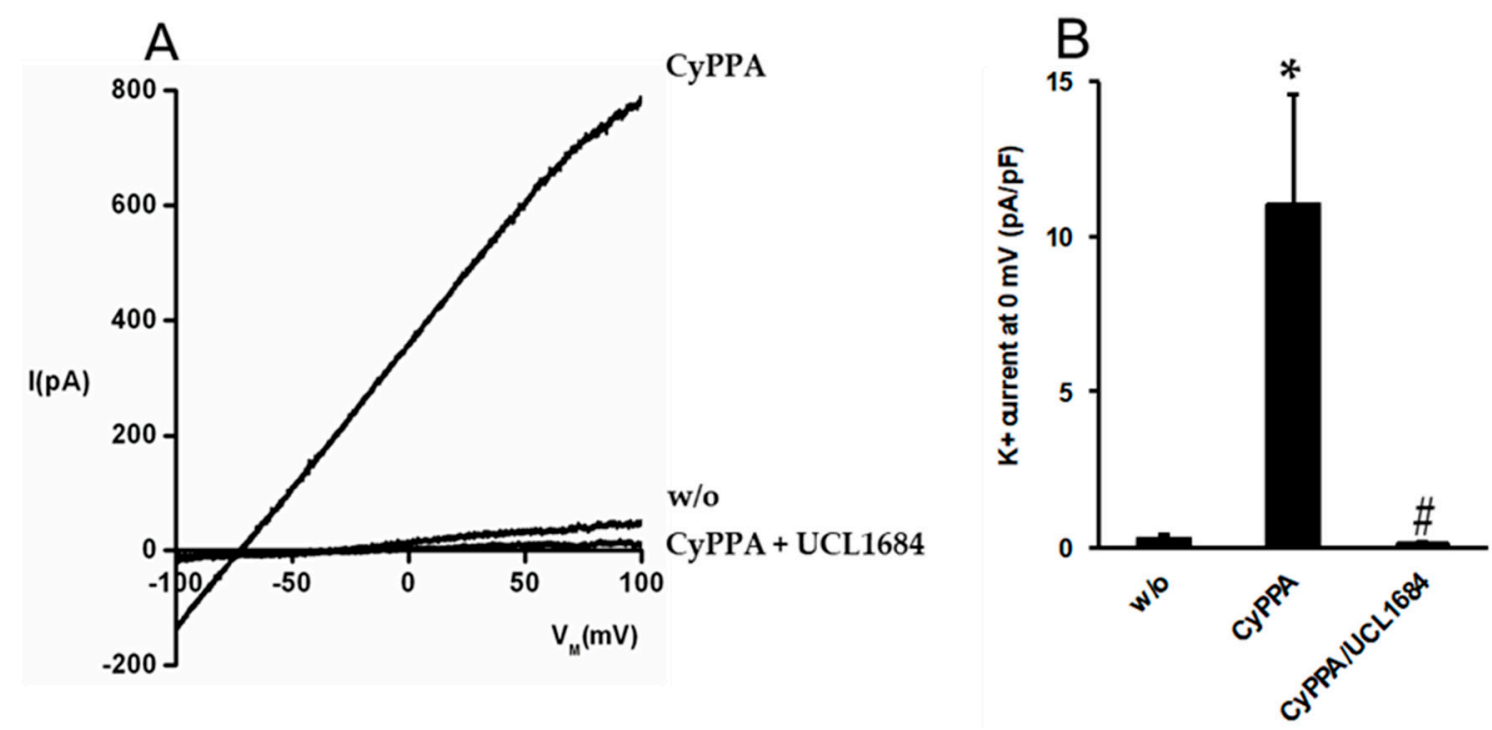

Figure 3. Activation of SKCa currents in porcine arterial endothelial cells by CyPPA. (A) Representative whole-cell currents in the absence (w/o) and in the presence of CyPPA $(10 \mu \mathrm{M})$ as well as inhibition of the CyPPA-activated currents by the SKCa blocker, UCL-1684 $(1 \mu \mathrm{M})$. (B) Average data are given as means \pm S.E.M. (CyPPA, $n=4$; UCl1684, $n=3$ ); ${ }^{*} p<0.05$ vs. w/o; $\# p<0.05$ vs. CyPPA.

In primary endothelial cells isolated from porcine coronary arteries, CyPPA $(10 \mu \mathrm{M})$ consistently induced large outward $\mathrm{K}^{+}$currents, shifting the reversal potential towards negative values near the $\mathrm{K}^{+}$ equilibrium potential. The apamin-mimicking non-peptidic blocker of SKCa channels, UCL1684 [32], fully blocked this current (Figure 3B). These data demonstrate that CyPPA is capable of opening SKCa channels in porcine primary endothelial cells.

\subsection{Effect of L-arginine on Endothelium-Dependent Relaxation}

Previous studies have shown that endothelium-derived NO may play an important role in basal tone of retinal arterioles [13]. To investigate the role of SKCa channels and L-arginine for basal endothelium-derived NO release, the effect on basal tone was studied. The porcine retinal arterioles developed myogenic tone $(n=9)$, which was increased in the presence of ADMA (300 $\mu \mathrm{M}, n=7)$, an inhibitor of NO synthase, suggesting basal release of NO. An opener of SKCa channels, CyPPA $(6 \mu \mathrm{M}, n=6)$ decreased myogenic tone, while it remained unchanged in the presence of apamin $(0.5 \mu \mathrm{M}, n=8)$ (Figure $4 \mathrm{~A})$. The myogenic tone was decreased in the presence of L-arginine $(100 \mu \mathrm{M}$, $n=9)$ alone, while it was unchanged in the presence of the combination of L-lysine $(600 \mu \mathrm{M})(n=9)$ and L-arginine $(100 \mu \mathrm{M})$ and of low $\mathrm{Na}^{+}(n=9)$ plus L-arginine $(100 \mu \mathrm{M})$ (Figure $\left.4 \mathrm{~B}\right)$. These findings suggest that both $\mathrm{L}$-arginine and the activation of SKCa channels by CyPPA increase basal release of NO in retinal arteries. 

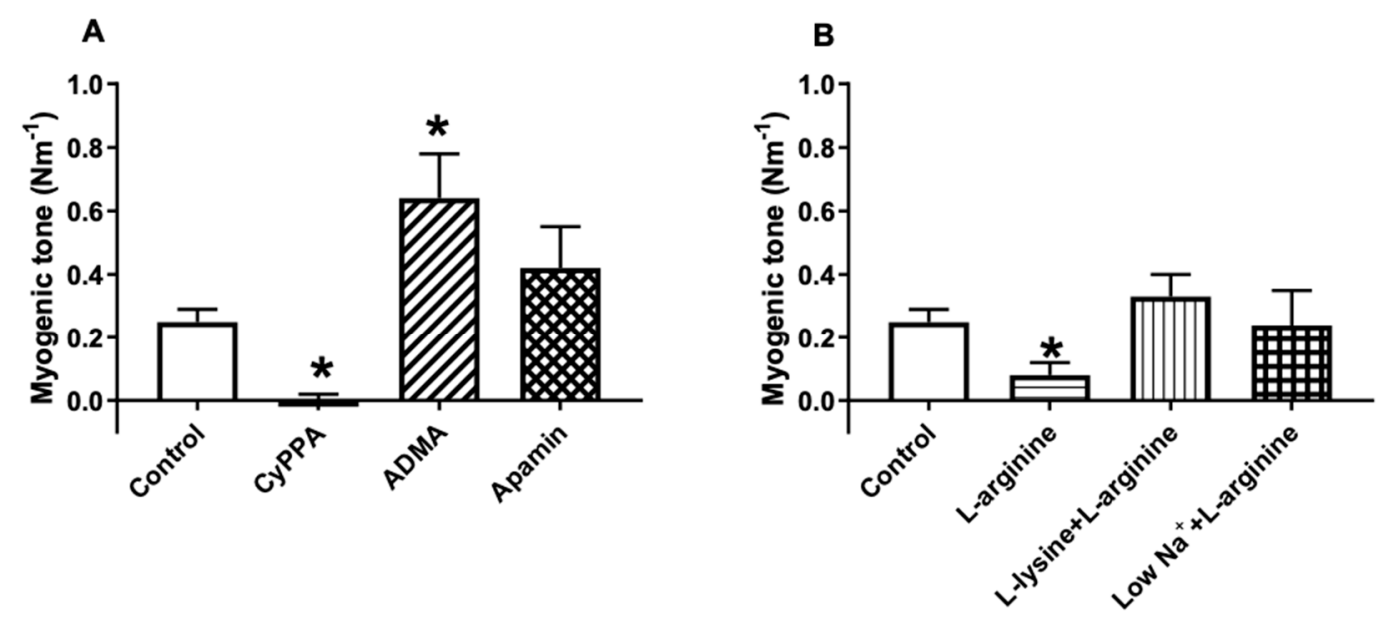

Figure 4. Pharmacological modulation of myogenic tone in porcine retinal arteries by (A) an opener of SKCa channels, CyPPA ( $6 \mu \mathrm{M}, n=6)$, an inhibitor of NO synthase, asymmetric dimethylarginine (ADMA, $100 \mu \mathrm{M}, n=7)$, and a blocker of SKCa channels, apamin $(0.5 \mu \mathrm{M}, n=8)$ and by (B) substrate for NO synthase, L-arginine $(100 \mu \mathrm{M}, n=9)$, and L-arginine in the presence of blockers of the $\mathrm{y}^{+}$transporter, L-lysine $(600 \mu \mathrm{M}, n=9)$ or low $\mathrm{Na}^{+}$-PSS $(n=9)$. Data are means \pm S.E.M. ${ }^{*} p<0.05$ vs. control.

In porcine retinal arterioles contracted with U46619 $(0.1 \mu \mathrm{M})$, L-arginine $(1 \mu \mathrm{M}-3 \mathrm{mM})$ alone $(n=5)$ or with CyPPA $(6 \mu \mathrm{M})(n=5)$ did not induce relaxation (Figure A1). In the presence of the inhibitor of eNOS, ADMA $(300 \mu \mathrm{M})(n=7)$, L-arginine induced small relaxations with a maximum of $25 \pm 4 \%(n=7)$ at $3 \mathrm{mM}$ L-arginine (Figure A1). These findings suggest that L-arginine in the absence and the presence of activation of SKCa channels are not involved in endothelium-derived modulation of agonist-induced contraction. However, in the presence of the inhibitor of eNOS, ADMA, L-arginine, by competition, is able to reverse the inhibitory effect of ADMA on eNOS-derived NO.

The opener of SKCa channels, CyPPA $(1 \mu \mathrm{M}-30 \mu \mathrm{M})$ induced concentrations-dependent relaxations $\left(\mathrm{pD}_{2}: 5.18 \pm 0.03, n=8\right)$ in porcine retinal arterioles. In the presence of ADMA $(300 \mu \mathrm{M})$ or apamin $(0.5 \mu \mathrm{M})$, concentration-response curves for CyPPA were significantly rightward shifted with $\mathrm{pD}_{2}$-values of, respectively, $4.96 \pm 0.04(n=7)$ and $4.66 \pm 0.08(n=8, p<0.05)$ suggesting that the opening of SKCa channels causes relaxation through a mechanism involving $\mathrm{NO}$. In the presence of L-arginine $(100 \mu \mathrm{M})$, concentration-response curves for CyPPA were leftward shifted with $\mathrm{pD}_{2}$ values of $5.36 \pm 0.02(p<0.05$ versus control, $n=9)$. This enhanced relaxation was abolished by inhibiting the L-arginine uptake through the $\mathrm{y}^{+}$transporter system with L-lysine $(600 \mu \mathrm{M})\left(\mathrm{pD}_{2}: 5.22 \pm 0.02, n=9\right)$, but not when normal PSS was replaced with low $\mathrm{Na}^{+}$containing PSS to inhibit the L-arginine uptake through the $\mathrm{Bo},+$ transporter system $\left(\mathrm{pD}_{2}: 5.41 \pm 0.01, n=9\right)$ (Figure 5$)$. These findings suggest that increasing extracellular L-arginine via the $\mathrm{y}^{+}$transporter system contributes to NO-mediated relaxation induced by pharmacological activation of SKCa channels.

Bradykinin induces relaxations in porcine retinal arteries via $\mathrm{B}_{2}$ receptor-signaling. These relaxations can be blocked by inhibitors of eNOS and cyclooxygenase [13]. In the present study, bradykinin $(0.01 \mathrm{nM}-0.3 \mu \mathrm{M})$ induced concentration-dependent relaxations $\left(\mathrm{pD}_{2}: 8.72 \pm 0.07\right.$, $n=6)$ (Figure A2). In the presence of CyPPA $(6 \mu \mathrm{M})$, these relaxations were enhanced $\left(\mathrm{pD}_{2}: 9.56 \pm 0.05\right.$, $n=7)$. In contrast, L-arginine $(100 \mu \mathrm{M})$ did not change bradykinin-induced relaxations neither alone $\left(\mathrm{pD}_{2}: 8.67 \pm 0.03, n=6\right)$ nor in the presence of CyPPA $\left(\mathrm{pD}_{2}: 9.71 \pm 0.05, n=6\right)($ Figure A2) These findings suggest that the opening of SKCa channels enhances bradykinin relaxation, while extracellular L-arginine does not. 


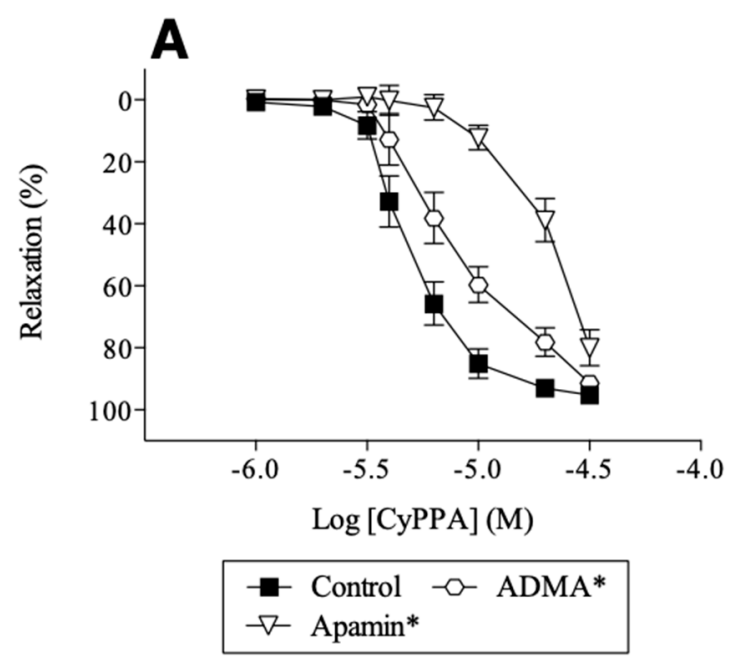

B

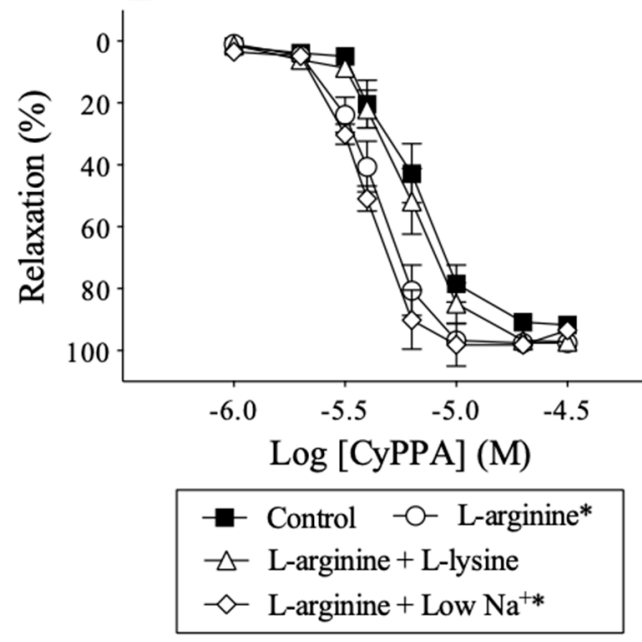

Figure 5. Modulation of CyPPA-induced relaxation in porcine retinal arterioles by (A) ADMA (300 $\mu$ M), an inhibitor of NO synthase, apamin $(0.5 \mu \mathrm{M})$, a blocker of SKCa channels, by (B) L-arginine $(100 \mu \mathrm{M})$, L-lysine $(600 \mu \mathrm{M})$, and low $\mathrm{Na}^{+}$-PSS. Data are means \pm S.E.M. $(n=7-9)$. Two-way ANOVA. ${ }^{*} p<0.05$ vs. control.

\section{Discussion}

Our results suggest that in porcine retinal arterioles, eNOS, SKCa3, and CAT-1 protein are co-localized in the vascular endothelium, and that L-arginine enhances NO mediated relaxation induced by activating SKCa channels, an effect mediated by the $\mathrm{L}$-arginine uptake through the $\mathrm{y}^{+}$ transporter system. Supporting these findings, acetylcholine-induced ${ }^{3} \mathrm{H}$-L-arginine uptake in rat aortic valve endothelial cells was abolished by blocking the SKCa and IKCa channels or the $\mathrm{y}^{+}$transporter system (Figure 1).

Previous studies report that the majority of eNOS is located in the membrane fraction of endothelial cells, with only a small fraction localized in the cytosol. More specifically, eNOS is localized in caveolae of the endothelial plasma membranes $[33,34]$ and the enzymatic activity of eNOS is primarily particulate and found in caveolar rich parts of the membrane [35]. In electron microscopy, we have observed that SKCa3 channels are expressed in the apical and lateral membrane of endothelial cells in the tissue [36]. Moreover, SKCa3 channels in isolated endothelial cells is in close proximity to caveolin-1, eNOS, and G-protein coupled receptors, such as the bradykinin receptor [37]. These results suggest that SKCa3 and eNOS may co-localize within caveolae of the endothelial cells. For the CAT systems, which are responsible for the uptake of extracellular L-arginine, five transporter proteins have been characterized 
(CAT-1, CAT-2A, CAT-2B, CAT-3, and CAT-4) [27], and they are categorized into two classes based on their $\mathrm{Na}^{+}$dependence. The carrier proteins mediating $\mathrm{Na}^{+}$-independent transport of cationic amino acids include the systems $\mathrm{y}^{+}, \mathrm{y}^{+} \mathrm{L}, \mathrm{bo}^{+}, \mathrm{b}^{+}$, where uptake of cationic amino acids occurs via carrier-mediated passive-facilitated diffusion. The carrier proteins mediating $\mathrm{Na}^{+}$-dependent transport of cationic amino acids include the Bo, + system, where uptake of cationic amino acids is coupled with the plasma membrane $\mathrm{Na}^{+}$electrochemical gradient generated by the $\mathrm{Na}^{+} / \mathrm{K}^{+}$ATPase [38] The majority of L-arginine enters endothelial cells through the CAT-1 y+ transporter system [25,27], and immunohistochemistry and immunoprecipitation showed that the CAT-1 exists in a complex with eNOS in plasmalemmal caveolae from porcine pulmonary arterial endothelial cells [39], and interact directly in bovine aortic endothelial cell culture [38]. The L-arginine uptake appears to involve the membrane potential, in which hyperpolarization increases and depolarization decreases the uptake $[29,30]$. In agreement with these findings, we found that eNOS partly co-localized with SKCa3 and CAT-1 (Figure 2) indicating that these proteins may exist as a microdomain and interact in porcine retinal arteriolar endothelial cells.

Previous studies have found that relaxation by eNOS activation induced by stretch, isometric contration, cAMP, and isoprenaline, but not acetylcholine, is dependent on extracellular L-arginine in rat pulmonary arteries $[40,41]$. A possible explanation for this discrepancy between these results may be the co-localization of eNOS and CAT-1 within caveolae of endothelial cell [38]. Stretch, isometric contraction, cAMP, and isoprenaline are dependent on extracellular L-arginine through CAT-1 [42], whereas acetylcholine causes translocation of eNOS into the cytosol allowing access to the cytosolic L-arginine pool $[43,44]$, minimizing extracellular L-arginine dependence. Supporting these findings, this study found that the myogenic tone was reduced by L-arginine and SKCa channel activation, and increased by eNOS inhibition (Figure 4). Moreover, L-lysine and low Na+-PSS, normalized the reduced myogenic tone induced by L-arginine. These results suggest that the NO mediated regulation of myogenic tone may be dependent on extracellular L-arginine and SKCa channel activity.

A decreased NO bioavailability associated with endothelial dysfunction in cardiovascular diseases may be caused by a limited L-arginine supply $[27,44]$, and many animals studies and clinical studies show that L-arginine supplementation improves endothelium-dependent vasodilatation. However, an equal or perhaps even larger number of studies show that L-arginine supplementation has no effect [44]. This problem is termed the L-arginine paradox, and is based on the observation that an increase in extracellular L-arginine concentration from 0.1 to $10 \mathrm{mM}$ increases NO production, despite that $\mathrm{Km}$ for eNOS for L-arginine is approximately $10 \mu \mathrm{M}$, and that intracellular L-arginine concentrations range between 100 and $800 \mu \mathrm{M}$ [27]. One explanation may be that L-arginine is sequestered in pools or compartments that are poorly accessible to eNOS. This leaves the extracellular L-arginine as a regulative substrate for eNOS. Alternatively, changes in the levels of the endogenous inhibitor of eNOS, ADMA, by competition inhibits L-arginine uptake by the $y+$ transporter. We have previously found that in superior mesenteric arteries from renal hypertensive rats, treatment with L-arginine did not restore NO bioavailability [45]. The present results support this, since L-arginine itself did not induce relaxation and had no effect on bradykinin-induced relaxation of pre-contracted arterioles neither alone nor when CyPPA, an activator of SKCa2-3 channels, enhanced bradykinin-induced relaxation. These results indicate that L-arginine supplementation per se does not improve endothelium-dependent vasodilatation in the presence of a vasoconstrictor. However, in the presence of ADMA, L-arginine induced relaxation supporting that ADMA and L-arginine compete for uptake, indicating that increasing concentrations of L-arginine decreased the eNOS inhibiting effect of ADMA. These findings suggest that L-arginine supplementation may be beneficial when ADMA levels are elevated.

We have previously reported that activating SKCa channels with CyPPA leads to endotheliumdependent relaxation that is only mediated by NO [14]. In this study, we found L-arginine enhanced CyPPA-induced relaxations which were blocked by the y+ transport inhibitor, L-lysine. Moreover, the patch clamp experiments in the present study provide direct evidence that CyPPA opens endothelial SKCa channels in porcine primary endothelial cells. Thus, our findings suggest that the activation 
of SKCa channels through endothelial cell hyperpolarization leads to increased uptake of L-arginine through the $\mathrm{y}^{+}$transporter system and this is followed by increased NO production.

In conclusion, in porcine retinal arterioles, eNOS, SKCa3, and CAT-1 proteins were localized in the vascular endothelium. L-arginine increased NO mediated relaxation induced by activation of SKCa channels by a mechanism sensitive to inhibition of the $\mathrm{y}^{+}$transporter system. Moreover, in rat aortic valve endothelial cells acetylcholine-induced ${ }^{3} \mathrm{H}$-L-arginine uptake in rat aortic valve endothelial cells was abolished by blocking the SKCa and IKCa channels and the $\mathrm{y}^{+}$transporter system. Taken together, these results suggest that SKCa channel activity regulates L-arginine uptake through the $\mathrm{y}^{+}$ transporter system. From a clinical perspective, we propose that L-arginine supplementation alone may not necessarily prevent or restore endothelial dysfunction in cardiovascular disease. In fact, NO donors for instance nitroglycerin do not dilate retinal arteries in patients [46]. Therefore, in patients with retinal diseases, such as age-related macular degeneration, primary open angle glaucoma, and diabetic retinopathy [1-4], further investigation must clarify whether it is beneficial to combine endothelial SKCa channel activators with L-arginine supplementation to increase the L-arginine uptake and enhance NO mediated relaxation, and hence increase retinal blood flow.

\section{Materials and Methods}

All experiments conformed to guidelines from the European Convention for the Protection of Vertebrate Animals used for Experimental and other Scientific Purposes and were approved by and conducted with permission from Danish Institutional Animal Care and Use Committee, the Danish Ministry of Environment and Food (\#2011/561-2011 from 21 April 2011 and \#2014-15-2934-01059 from 19 May 2014).

\subsection{L-arginine Uptake}

In human umbilical vein endothelial cells (HUVECs), the NOS expression decreases markedly from freshly isolated cells to cultured endothelial cells [47]. Therefore, ${ }^{3} \mathrm{H}$-L-arginine uptake was intended in isolated small arteries, but the method did not allow to distinguish L-arginine uptake in vessels with and without endothelium. Therefore, to investigate L-arginine uptake in only in situ endothelial cells, fresh aortic mitral valves from the rat heart were isolated and incubated in physiological saline solution (PSS, see composition below) in an Eppendorf vial. To measure the time-dependent uptake of L-arginine, $20 \mathrm{nM}^{3} \mathrm{H}$-L-arginine was added to the vial oxygenated with a gas mixture of $5 \% \mathrm{CO}_{2}, 21 \%$ $\mathrm{O}_{2}$, and $74 \% \mathrm{~N}_{2}$, and kept in a bath heated to $37^{\circ} \mathrm{C}$. After 5, 10, and $20 \mathrm{~min}$, the valves were transferred to a plastic tube containing scintillation liquid, and the $\beta$ emission was measured in a scintillation counter (Model: LS6000, Beckman Coulter Inc., Brea, CA, USA). To investigate the role of potassium channels for the L-arginine uptake, the valves were incubated with acetylcholine $(10 \mu \mathrm{M})$ for $10 \mathrm{~min}$ in the absence or the presence of apamin $(0.5 \mu \mathrm{M})$ plus charybdotoxin $(0.1 \mu \mathrm{M})$, low sodium PSS, or low $\mathrm{Na}^{+}$-PSS with L-lysine $(600 \mu \mathrm{M})$ to block the $\mathrm{y}+$ transporter.

\subsection{Isolation of Pig Eyes}

From a local abattoir (Horsens, Denmark), eyes were obtained from 6 month-old pigs with a weight of $85-90 \mathrm{~kg}$. Immediately after the pigs had been exposed to carbon dioxide $\left(\mathrm{CO}_{2}\right)$ and sacrificed by exsanguination, one eye was removed from each animal and placed in a container with cold $\left(4{ }^{\circ} \mathrm{C}\right)$ physiological saline solution (PSS) of the composition (mM): $4.8 \mathrm{KCl}, 1.14 \mathrm{MgSO}_{4}, 118 \mathrm{NaCl}$, $25 \mathrm{NaHCO}_{3}, 5 \mathrm{HEPES}, 5.5$ glucose, and $1.6 \mathrm{CaCl}_{2}$. The eyes were transported to the laboratory, where they were dissected and the retinas isolated as previously described [14]. The eyes were opened, and the retina was detached from the underlying pigment epithelium. An arteriolar segment with a length of approximately $2 \mathrm{~mm}$ was dissected from the retina approximately $1-2 \mathrm{~mm}$ from the optic disk. 


\subsection{Immunohistochemistry}

Arteriolar segments with surrounding retinal tissue were fixed in cold $\left(4{ }^{\circ} \mathrm{C}\right) 4 \%$ paraformaldehyde, $\mathrm{pH} 7.0$ for $1 \mathrm{~h}$ for immunohistochemical processing. The segments were placed in $8 \%$ agar prior to embedding in paraffin. Longitudinal sections of $3 \mu \mathrm{m}$ were cut on a microtome. The sections were placed on glass slides, heated at $80^{\circ} \mathrm{C}$ for $1 \mathrm{~h}$, and de-paraffinized in xylene and decreasing concentrations of ethanol. To evaluate the distribution of SKCa3, eNOS, CAT-1, and smooth muscle actin protein, the sections were rinsed with phosphate buffered saline (PBS: $1.5 \mathrm{M} \mathrm{NaCl}, 0.5 \mathrm{M} \mathrm{NaH}_{2} \mathrm{PO}_{4}$ ), transferred to a $10 \mathrm{mM}$ citrate buffer $(5.0 \mathrm{mM}$ trisodiumcitrate dehydrate, $5.0 \mathrm{mM}$ disodiumhydrogencitrate, $\mathrm{pH}$ 6.0), heated in the microwave for $2 \times 7 \mathrm{~min}$ and rinsed with PBS. The sections were transferred to $0.2 \%$ Triton X solution for $10 \mathrm{~min}$ and then rinsed with PBS. In order to block non-specific antibody binding, the sections were incubated with 10\% fetal calf serum in PBS with 1\% BSA for 20 min. Incubation was done overnight in a humidified chamber at $4{ }^{\circ} \mathrm{C}$ with primary antibodies. Antibodies for SKCa3 protein (1:400, Antibodies-online $\mathrm{GmbH}$, Aachen, Germany), eNOS protein (1:50, BD Biosciences, Franklin Lakes, NJ, USA), CAT-1 protein (1:100, SLC7A1, Proteintech Group, Chicago, IL, USA), and smooth muscle actin protein (1:500, Dako, Glostrup, Denmark) were applied in PBS containing $1 \%$ bovine serum albumin (BSA). Negative controls for each sample section were without primary antibody. The sections were rinsed with PBS. They were then incubated for $1 \mathrm{~h}$ at room temperature with a secondary antibody, goat anti-rabbit IgG coupled to Alexa 488 (dilution 1:2000, Molecular Probes Inc., Eugene, OR, USA) or goat anti-mouse IgG coupled to Alexa 633 (dilution 1:2000, Molecular Probes Inc., Eugene, OR, USA) with PBS containing 1\% BSA for $1 \mathrm{~h}$ followed by rinsing with PBS. Finally, a cover slip was mounted after addition of antifade solution (Bio-Rad Laboratories Ltd., Hemel Hempstead, UK). The preparations were analyzed on an inverted confocal microscopy (LSM 510 Meta, Carl Zeiss Inc, Oberkochen, Germany) equipped with an oil immersion objective (C-Aprochromat $63 \times \mathrm{NA}=0.75$ ) excited at a wavelength of 488 or $633 \mathrm{~nm}$ and analyzed using the Zeiss Zen Image Browser software program (Zeiss Inc, Oberkochen, Germany).

\subsection{Patch Clamp Experiments in Endothelial Cells}

Porcine arterial endothelial cells were isolated as described previously [48]. In brief, porcine coronary arteries were cut open longitudinally and incubated for $30 \mathrm{~min}$ in phosphate-buffered saline w/o Ca ${ }^{2+} / \mathrm{Mg}^{2+}$ containing trypsin/EDTA $(0.25 \% / 0.02 \%, w / v)$. Thereafter, the luminal surface was gently scrapped with the tip of a $100 \mu \mathrm{L}$ pipette tip. Detached endothelial cells were aspirated and plated on cover slips in Modified Eagle Medium supplemented with 10\% newborn calf serum and penicillin/streptomycin (all from Biochrom KG, Berlin, Germany). Whole cell currents were recorded with an EPC10-USB patch-clamp amplifier and the PatchmasterTM software (HEKA Electronics, Germany) using voltage-ramps ( -100 to $100 \mathrm{mV}, 1 \mathrm{sec}$, filter $1000 \mathrm{~Hz}$ ). $\mathrm{K}^{+}$outward currents were quantified at a potential of $0 \mathrm{mV}$ before (w/o), after addition of CyPPA, and after addition of UCL1684 (both from Tocris Bioscience). The KCl-pipette solution was composed of (in mM): $140 \mathrm{KCl}, 1 \mathrm{MgCl}_{2}$, 2 EGTA, $1.71 \mathrm{CaCl}_{2}\left(1 \mu \mathrm{M}\left[\mathrm{Ca}^{2+}\right]_{\text {free }}\right)$, and 5 HEPES (adjusted to $\mathrm{pH} 7.2$ with $\left.\mathrm{KOH}\right)$. The bath solutions was composed of (in mM): $140 \mathrm{NaCl}, 5 \mathrm{KCl}, 1 \mathrm{MgSO}_{4}, 1 \mathrm{CaCl}_{2}, 10$ glucose and $10 \mathrm{HEPES}$ (adjusted to pH 7.4 with $\mathrm{NaOH})$.

\subsection{Functional Studies in Porcine Retinal Arterioles}

An isolated arteriolar segment was transferred to a chamber of a dual wire myograph system (model 410A, Danish MyoTechnology, Aarhus, Denmark) for isometric tension recording. For recording the system was coupled to the Chart5 software program (ADInstruments Ltd., Oxfordshire, UK). Each arteriole was mounted in the myograph using two $25 \mu \mathrm{m}$ tungsten wires and was allowed to equilibrate for $30 \mathrm{~min}$ at $37^{\circ} \mathrm{C}$ in PSS bubbled with artificial air of the following composition: $5 \% \mathrm{CO}_{2}$, $21 \% \mathrm{O}_{2}$, and $74 \% \mathrm{~N}_{2}$. Subsequently, the arterial segments were stretched in PSS without $\mathrm{CaCl}_{2}$ (PSS0.0) to an internal circumference corresponding to $94 \%$ of the tone at a transmural pressure of $70 \mathrm{mmHg}$ [49]. 
After setting the passive tension, PSS0.0 was replaced with PSS, and the segment was allowed to equilibrate for another $30 \mathrm{~min}$. The internal diameter of the arterioles used for functional studies averaged $118 \pm 2 \mu \mathrm{m}(n=79)$.

To test smooth muscle cell viability potassium-rich PSS (KPSS) was added to test contraction by smooth muscle cell depolarization. KPSS was PSS, where equimolar concentration of $\mathrm{NaCl}$ was replaced with $\mathrm{KCl}$ giving a concentration of $60 \mathrm{mM} \mathrm{K}+$. Moreover, 9, 11-dideoxy-11a, 9a-epoxymethano-prostaglandin $\mathrm{F}_{2 \alpha}(\mathrm{U} 46619,0.1 \mu \mathrm{M})$ was added to examine contraction induced by activation of the thromboxane $A_{2}$ receptor. The arterioles were discarded, if U46619 contraction was less than $0.25 \mathrm{Nm}^{-1}$. To test endothelial function, bradykinin $(0.03 \mu \mathrm{M})$ was added in $\mathrm{U} 46619$ $(0.1 \mu \mathrm{M})$-contracted arterioles. The arteries were discarded if bradykinin relaxation was less than $50 \%[13]$.

After control of viability, the segments were contracted with $\mathrm{U} 46619(0.1 \mu \mathrm{M})$ and concentrationresponse curves were obtained by cumulative additions of L-arginine $(1 \mu \mathrm{M}-3 \mathrm{mM})$ bradykinin $(0.01 \mathrm{nM}-0.3 \mu \mathrm{M})$, and CyPPA $(1-30 \mu \mathrm{M})$. To investigate the contribution from NO synthase in the concentration-response experiments, the segments were incubated with the NO synthase inhibitor, asymmetric dimethylarginine (ADMA, $300 \mu \mathrm{M})$ [45] or L-arginine $(100 \mu \mathrm{M})$ [50] $30 \mathrm{~min}$ prior to contraction. To investigate the role of $\mathrm{Na}^{+}$-dependent $(\mathrm{Bo},+)$ and independent $(\mathrm{y}+) \mathrm{CAT}$ system, the preparations were incubated with L-lysine $(600 \mu \mathrm{M})$ to inhibit L-arginine uptake through the CAT systems $[40,41]$ or low $\mathrm{Na}^{+}$-PSS to inhibit the $\mathrm{Na}^{+}$-dependent $(\mathrm{Bo},+)$ CAT system, where $\mathrm{NaCl}$ was replaced with choline chloride. To investigate the effect of activating SKCa channels on bradykinin-induced relaxation, CyPPA $(6 \mu \mathrm{M})$ was added to the organ bath after the segments were contracted with $\mathrm{U} 46619(0.1 \mu \mathrm{M})$ and then concentration-response curves for L-arginine or bradykinin were obtained [13].

\subsection{Drugs and Solutions}

Xylene, Meyer's haematoxylin and eosin for histological stainings were obtained from Bie \& Berntsen, Herlev, Denmark. Fetal calf serum was purchased at Biochrom, Berlin, Germany. Triton X and BSA were purchased at Sigma Aldrich, St. Louis, MO, USA. U46619, ADMA, bradykinin, L-arginine, and L-lysine were from Sigma Aldrich, St. Louis, MO, USA. CyPPA (cyclohexyl-[2-(3,5-dimethyl-pyrazol-1-yl)-6-methyl-pyrimidin-4-yl]-amine) was a donation from Dr. Søren-Peter Olesen, Neurosearch A/S, Ballerup, Denmark. U46619 was dissolved in ethanol. CyPPA was dissolved in DMSO (99\%), and bradykinin in distilled water. Bradykinin was prepared in $2 \%$ albumin-coated Eppendorf tubes.

\subsection{Data and Statistical Analysis}

The Zeiss Zen Image Browser software program (Zeiss Inc, Oberkochen, Germany) was used for the immunolabeling and co-localization analysis. Based on these analyses, weighted co-localization coefficients were calculated. The sum of intensities of co-localizing pixels in channel 1 or 2, respectively, was compared to the overall sum of pixel intensities above threshold. Value range 0-1 (0: no co-localization, 1: all pixels co-localize). Bright pixels were considered to contribute more than faint pixels.

For ${ }^{3} \mathrm{H}$-L-arginine uptake experiments the measurements are given as counts per min (cpm). For functional studies, myogenic tone was calculated as the change in tension after the normalization procedure and after $30 \mathrm{~min}$ of incubation with inhibitors. In the concentration-response experiments, relaxations were calculated as the tension in the peak response after each addition of bradykinin, while for L-arginine or CyPPA the stable tension after each addition were expressed as percentage of the active tension. The active tone was defined as the level of contraction after the addition of U46619 subtracted by the level of contraction after the passive stretch of the preparations. For bradykinin curves obtained in the presence of СуРPA, the active tone was defined as the level of contraction 
after addition of U46619 and CyPPA subtracted by the level of contraction after passive stretch of the preparations.

All data are means \pm S.E.M. with a significance level of $p<0.05 . n$ represents the number of segments from individual animals. Concentration-response curves were compared by use of two-way ANOVA. One-way ANOVA followed by Bonferroni post-hoc test was used for evaluation of differences in ${ }^{3} \mathrm{H}$-L-arginine uptake and in myogenic tone experiments. All data were analyzed using GraphPad Prism 7.0 software (GraphPad software Inc., La Jolla, CA, USA).

Author Contributions: U.S. and A.K.W. designed the protocols and performed the L-arginine uptake experiments and experiments in retinal arteries. R.K. and A.O.-V. performed and analyzed patch-clamp experiments and revised the manuscript. U.S., A.K.W., S.C.-S. and T.B. took part in the conception, designed the study and completed the manuscript writing.

Funding: U. Simonsen was supported by the NovoNordisk Foundation (NNF160C0023284) and the Danish Research Council (DFF 6110-00622). RK and AOV are supported by a grant of the Aragonese Government (Consortium MECIT, B04_17R) co-financed by the European Regional Development Fund 2014-2020: "Construyendo Europa desde Aragón".

Acknowledgments: We thank Christel Kroigaard and Thomas Dalsgaard for technical assistance and helpful discussions, and technician Henriette Gram Johanson and Anna Malgorzata Jurkiewicz for excellent technical assistance.

Conflicts of Interest: The authors declare no conflict of interest. The funders had no role in the design of the study; in the collection, analyses, or interpretation of data; in the writing of the manuscript, or in the decision to publish the results.

\section{Abbreviations}

$\begin{array}{ll}\text { ADMA } & \begin{array}{l}\text { Asymmetric dimethylarginine } \\ \text { CAT-1 }\end{array} \\ \text { cationic amino acid transporter } \\ \text { cyPPA } & \text { Endohexyl-[2-(3,5-dimethyl-pyrazol-1-yl)-6-methyl-pyrimidin-4-yl]-amine } \\ \text { EDH } & \text { Endothelial nitric oxide synthase } \\ \text { eNOS } & \mathrm{Ca}^{2+} \text {-activated K channels with intermediate conductance (KCa3.1) } \\ \text { IKCa } & \mathrm{Nitric}^{2+} \text { oxide } \\ \text { NO } & \mathrm{Ca}^{2+} \text {-activated K channels with small conductance (KCa2.1-3) } \\ \text { SKCa } & \text { Blocker of } \mathrm{Ca}^{2+} \text {-activated K channels (KCa2.1-3) }\end{array}$

\section{Appendix A}

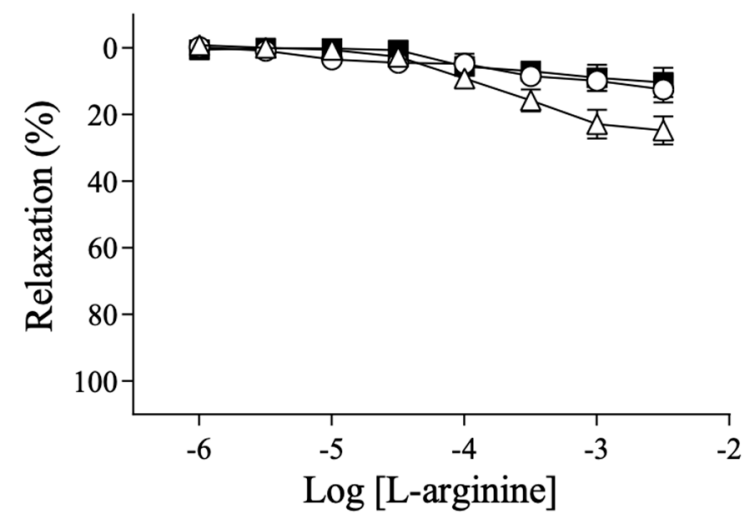

$\neg$ Control $-\mathrm{O}$ CyPPA $\triangle$ ADMA* $^{*}$

Figure A1. L-arginine-induced relaxation in the absence and presence of CyPPA $(6 \mu \mathrm{M})$, an opener of SKCa2 and SKCa3 channels, or ADMA $(300 \mu \mathrm{M})$, an inhibitor of NO synthase, in U46619-contracted porcine retinal arterioles. Data are means \pm S.E.M. $(n=5-7)$. Two-way ANOVA. ${ }^{*} p<0.05$ vs. control. 


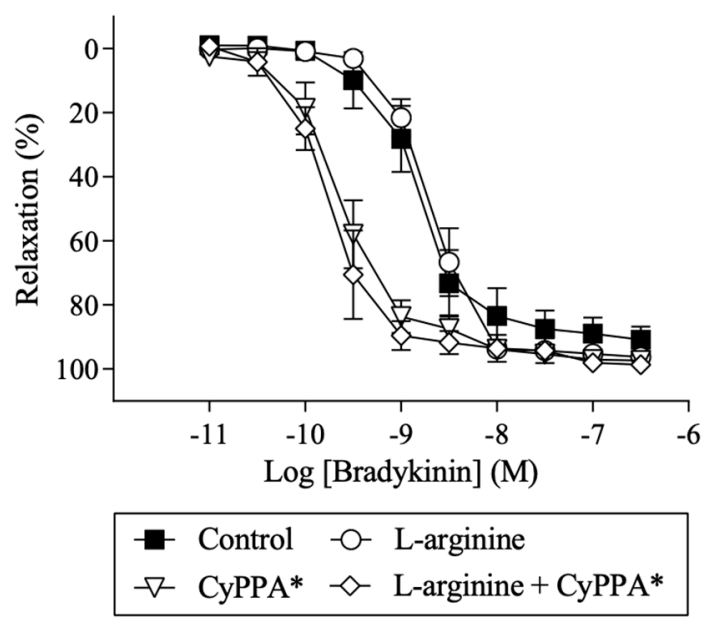

Figure A2. Bradykinin-induced relaxation in the absence and presence of L-arginine $(100 \mu \mathrm{M})$ and CyPPA $(6 \mu \mathrm{M})$, an activator of SKCa2-3 channels, in U46619-contracted porcine retinal arterioles. Data are means \pm S.E.M. $(n=6-7)$. Two-way ANOVA. ${ }^{*} p<0.05$ vs. control.

\section{References}

1. Bek, T. Inner retinal ischaemia: Current understanding and needs for further investigations. Acta Ophthalmol 2009, 87, 362-367. [CrossRef]

2. Ciulla, T.A.; Harris, A.; Martin, B.J. Ocular perfusion and age-related macular degeneration. Acta Ophthalmol. Scand. 2001, 79, 108-115. [CrossRef] [PubMed]

3. Kohner, E.M.; Patel, V.; Rassam, S.M.B. Role of blood flow and impaired autoregulation in the pathogenesis of diabetic retinopathy. Diabetes 1995, 44, 603-607. [CrossRef] [PubMed]

4. Petersen, L.; Bek, T. Preserved Pressure Autoregulation but Disturbed Cyclo-Oxygenase and Nitric Oxide Effects on Retinal Arterioles during Acute Hypoxia in Diabetic Patients without Retinopathy. Ophthalmologica 2016, 235, 114-120. [CrossRef] [PubMed]

5. Delles, C.; Michelson, G.; Harazny, J.; Oehmer, M.; Hilgers, K.F.; Schmieder, R.E. Impaired endothelial function of the retinal vasculature in hypertensive patients. Stroke 2004, 35, 1289-1293. [CrossRef]

6. Resch, H.G.; Garhofer, G.; Fuchsjäger-Mayrl, G.; Hommer, A.; Schmetterer, L. Endothelial dysfunction in glaucoma. Acta Ophthalmol. 2009, 87, 4-12. [CrossRef]

7. Schmetterer, L.; Findl, O.; Fasching, P.; Ferber, W.; Strenn, K.; Breiteneder, H.; Adam, H.; Eichler, H.G.; Wolzt, M. Nitric oxide and ocular blood flow in patients with IDDM. Diabetes 1997, 46, 653-658. [CrossRef]

8. Burnham, M.P.; Bychkov, R.; Félétou, M.; Richards, G.R.; Vanhoutte, P.M.; Weston, A.H.; Edwards, G. Characterization of an apamin-sensitive small-conductance $\mathrm{Ca}(2+)$-activated $\mathrm{K}(+)$ channel in porcine coronary artery endothelium: Relevance to EDHF. Br. J. Pharmacol. 2002, 135, 1133-1143. [CrossRef]

9. Bychkov, R.; Burnham, M.P.; Richards, G.R.; Edwards, G.; Weston, A.H.; Félétou, M.; Vanhoutte, P.M. Characterization of a charybdotoxin-sensitive intermediate conductance Ca2+-activated K+channel in porcine coronary endothelium: Relevance to EDHF. Br. J. Pharmacol. 2002, 137, 1346-1354. [CrossRef] [PubMed]

10. Eichler, I.; Wibawa, J.; Grgic, I.; Knorr, A.; Brakemeier, S.; Pries, A.R.; Hoyer, J.; Köhler, R. Selective blockade of endothelial Ca2+-activated small- and intermediate-conductance $\mathrm{K}+$-channels suppresses EDHF-mediated vasodilation. Br. J. Pharmacol. 2003, 138, 594-601. [CrossRef]

11. Alexander, S.P.H.; Kelly, E.; Marrion, N.V.; Peters, J.A.; Faccenda, E.; Harding, S.D.; Pawson, A.J.; Sharman, J.L.; Southan, C.; Davies, J.A. THE CONCISE GUIDE TO PHARMACOLOGY 2017/18: Other ion channels. Br. J. Pharmacol. 2017, 174, S195-S207. [CrossRef]

12. Vanhoutte, P.M.; Shimokawa, H.; Feletou, M.; Tang, E.H.C. Endothelial dysfunction and vascular disease - a 30th anniversary update. Acta Physiol. 2017, 219, 22-96. [CrossRef]

13. Dalsgaard, T.; Kroigaard, C.; Bek, T.; Simonsen, U. Role of calcium-activated potassium channels with small conductance in bradykinin-induced vasodilation of porcine retinal arterioles. Investig. Ophthalmol. Vis. Sci. 2009, 50, 3819-3825. [CrossRef] 
14. Dalsgaard, T.; Kroigaard, C.; Misfeldt, M.; Bek, T.; Simonsen, U. Openers of small conductance calcium-activated potassium channels selectively enhance NO-mediated bradykinin vasodilatation in porcine retinal arterioles. Br. J. Pharmacol. 2010, 160, 1496-1508. [CrossRef]

15. Jeppesen, P.; Aalkjaer, C.; Bek, T. Bradykinin relaxation in small porcine retinal arterioles. Investig. Ophthalmol. Vis. Sci. 2002, 43, 1891-1896.

16. Kulkarni, P.; Cai, J.; Hurst, H.E. Lipids and nitric oxide in porcine retinal and choroidal blood vessels. J. Ocul. Pharmacol. Ther. Off. J. Assoc. Ocul. Pharmacol. Ther. 2002, 18, 265-275. [CrossRef]

17. Nakazawa, T.; Kaneko, Y.; Mori, A.; Saito, M.; Sakamoto, K.; Nakahara, T.; Ishii, K. Attenuation of nitric oxide- and prostaglandin-independent vasodilation of retinal arterioles induced by acetylcholine in streptozotocin-treated rats. Vascul. Pharmacol. 2007, 46, 153-159. [CrossRef]

18. Hein, T.W.; Rosa, R.H.; Yuan, Z.; Roberts, E.; Kuo, L. Divergent roles of nitric oxide and rho kinase in vasomotor regulation of human retinal arterioles. Investig. Ophthalmol. Vis. Sci. 2010, 51, 1583-1590. [CrossRef]

19. Pournaras, C.J.; Rungger-Brändle, E.; Riva, C.E.; Hardarson, S.H.; Stefansson, E. Regulation of retinal blood flow in health and disease. Prog. Retin. Eye Res. 2008, 27, 284-330. [CrossRef]

20. Sheng, J.Z.; Ella, S.; Davis, M.J.; Hill, M.A.; Braun, A.P. Openers of SKCa and IKCa channels enhance agonist-evoked endothelial nitric oxide synthesis and arteriolar vasodilation. FASEB J. 2009, 23, 1138-1145. [CrossRef]

21. Stankevičius, E.; Lopez-Valverde, V.; Rivera, L.; Hughes, A.D.; Mulvany, M.J.; Simonsen, U. Combination of Ca 2+-activated $\mathrm{K}+$ channel blockers inhibits acetylcholine-evoked nitric oxide release in rat superior mesenteric artery. Br. J. Pharmacol. 2006, 149, 560-572. [CrossRef]

22. Stankevicius, E.; Dalsgaard, T.; Kroigaard, C.; Beck, L.; Boedtkjer, E.; Misfeldt, M.W.; Nielsen, G.; Schjorring, O.; Hughes, A.; Simonsen, U. Opening of Small and Intermediate Calcium-Activated Potassium Channels Induces Relaxation Mainly Mediated by Nitric-Oxide Release in Large Arteries and Endothelium-Derived Hyperpolarizing Factor in Small Arteries from Rat. J. Pharmacol. Exp. Ther. 2011, 339, 842-850. [CrossRef]

23. Gaete, P.S.; Lillo, M.A.; Ardiles, N.M.; Pérez, F.R.; Figueroa, X.F. Ca2+-activated K+channels of small and intermediate conductance control eNOS activation through NAD $(\mathrm{P}) \mathrm{H}$ oxidase. Free Radic. Biol. Med. 2012, 52, 860-870. [CrossRef]

24. Parnell, M.M.; Chin-Dusting, J.P.F.; Starr, J.; Kaye, D.M. In vivo and in vitro evidence for ACh-stimulated ${ }^{3} \mathrm{H}$-arginine uptake. Am. J. Physiol. Circ. Physiol. 2004, 287, H395-H400. [CrossRef]

25. Shin, S.; Mohan, S.; Fung, H.L. Intracellular l-arginine concentration does not determine NO production in endothelial cells: Implications on the l-arginine paradox'. Biochem. Biophys. Res. Commun. 2011, 414, 660-663. [CrossRef]

26. Delgado, E.; Marques-Neves, C.; Rocha, I.; Sales-Luís, J.; Silva-Carvalho, L. L-Arginine and L-Nitroarginine Methylester Effects on Vasomotion in Isolated Rabbit Eyes. Ophthalmic. Res. 2009, 43, 113-121. [CrossRef]

27. Chin-Dusting, J.P.F.; Willems, L.; Kaye, D.M. 1-Arginine transporters in cardiovascular disease: A novel therapeutic target. Pharmacol. Ther. 2007, 116, 428-436. [CrossRef]

28. Zani, B.G.; Bohlen, H.G. Transport of extracellular ${ }^{3} \mathrm{H}$-arginine via cationic amino acid transporter is required during in vivo endothelial nitric oxide production. Am. J. Physiol. Circ. Physiol. 2005, 289, H1381-H1390. [CrossRef]

29. Bogle, R.G.; Coade, S.B.; Moncada, S.; Pearson, J.D.; Mann, G.E. Bradykinin and ATP stimulate L-arginine uptake and nitric oxide release in vascular endothelial cells. Biochem. Biophys. Res. Commun. 1991, 180, 926-932. [CrossRef]

30. Zharikov, S.I.; Herrera, H.; Block, E.R. Role of membrane potential in hypoxic inhibition of L-arginine uptake by lung endothelial cells. Am. J. Physiol. 1997, 272, L78-L84. [CrossRef]

31. Hougaard, C.; Eriksen, B.L.; Jørgensen, S.; Johansen, T.H.; Dyhring, T.; Madsen, L.S.; Strøbæk, D.; Christophersen, P. Selective positive modulation of the SK3 and SK2 subtypes of small conductance Ca2+-activated K+channels. Br. J. Pharmacol. 2007, 151, 655-665. [CrossRef]

32. Campos Rosa, J.; Galanakis, D.; Piergentili, A.; Bhandari, K.; Ganellin, C.R.; Dunn, P.M.; Jenkinson, D.H. Synthesis, molecular modeling, and pharmacological testing of bis-quinolinium cyclophanes: Potent, non-peptidic blockers of the apamin-sensitive Ca(2+)-activated $\mathrm{K}(+)$ channel. J. Med. Chem. 2000, 43, 420-431. [CrossRef] 
33. Garcia-Cardena, G.; Oh, P.; Liu, J.; Schnitzer, J.E.; Sessa, W.C. Targeting of nitric oxide synthase to endothelial cell caveolae via palmitoylation: Implications for nitric oxide signaling. Proc. Natl. Acad. Sci. USA 1996, 93, 6448-6453. [CrossRef]

34. García-Cardeña, G.; Martasek, P.; Masters, B.S.S.; Skidd, P.M.; Couet, J.; Li, S.; Lisanti, M.P.; Sessa, W.C. Dissecting the interaction between nitric oxide synthase (NOS) and caveolin. Functional significance of the nos caveolin binding domain in vivo. J. Biol. Chem. 1997, 272, 25437-25440. [CrossRef]

35. Shaul, P.W.; Smart, E.J.; Robinson, L.J.; German, Z.; Yuhanna, I.S.; Ying, Y.; Anderson, R.G.W.; Michel, T. Acylation targets endothelial nitric-oxide synthase to plasmalemmal caveolae. J. Biol. Chem. 1996, 271, 6518-6522. [CrossRef]

36. Frank, P.G.; Woodman, S.E.; Park, D.S.; Lisanti, M.P. Caveolin, caveolae, and endothelial cell function. Arterioscler. Thromb. Vasc. Biol. 2003, 23, 1161-1168. [CrossRef]

37. Mann, G.E.; Yudilevich, D.L.; Sobrevia, L. Regulation of Amino Acid and Glucose Transporters in Endothelial and Smooth Muscle Cells. Physiol. Rev. 2003, 83, 183-252. [CrossRef]

38. Li, C.; Huang, W.; Harris, M.B.; Goolsby, J.M.; Venema, R.C. Interaction of the endothelial nitric oxide synthase with the CAT-1 arginine transporter enhances NO release by a mechanism not involving arginine transport. Biochem. J. 2005, 386, 567-574. [CrossRef]

39. McDonald, K.K.; Zharikov, S.; Block, E.R.; Kilberg, M.S. A caveolar complex between the cationic amino acid transporter 1 and endothelial nitric-oxide synthase may explain the 'arginine paradox'. J. Biol. Chem. 1997, 272, 31213-31216. [CrossRef]

40. Hucks, D.; Khan, N.M.; Ward, J.P.T. Essential role of L-arginine uptake and protein tyrosine kinase activity for NO-dependent vasorelaxation induced by stretch, isometric tension and cyclic AMP in rat pulmonary arteries. Br. J. Pharmacol. 2000, 131, 1475-1481. [CrossRef]

41. Hucks, D.; Ward, J.P.T. Critical dependence of the NO-mediated component of cyclic AMP-induced vasorelaxation on extracellular L-arginine in pulmonary arteries of the rat. Br. J. Pharmacol. 2000, 130, 997-1004. [CrossRef]

42. Goetz, R.M.; Thatte, H.S.; Prabhakar, P.; Cho, M.R.; Michel, T.; Golan, D.E. Estradiol induces the calcium-dependent translocation of endothelial nitric oxide synthase. Proc. Natl. Acad. Sci. USA 1999, 96, 2788-2793. [CrossRef]

43. Prabhakar, P.; Thatte, H.S.; Goetz, R.M.; Cho, M.R.; Golan, D.E.; Michel, T. Receptor-regulated translocation of endothelial nitric-oxide synthase. J. Biol. Chem. 1998, 273, 27383-27388. [CrossRef]

44. Böger, R.H. L-Arginine therapy in cardiovascular pathologies: Beneficial or dangerous? Curr. Opin. Clin. Nutr. Metab. Care 2008, 11, 55-61. [CrossRef] [PubMed]

45. Stankevicius, E.; Martinez, A.C.; Mulvany, M.J.; Simonsen, U. Blunted acetylcholine relaxation and nitric oxide release in arteries from renal hypertensive rats. J. Hypertens. 2002, 20, 1571-1579. [CrossRef]

46. Kaya, M.Y.; Petersen, L.; Bek, T. Lack of effect of nitroglycerin on the diameter response of larger retinal arterioles in normal persons during hypoxia. Graefe's Arch. Clin. Exp. Ophthalmol. 2016, 254, 277-283. [CrossRef]

47. Andersen, M.R.; Simonsen, U.; Uldbjerg, N.; Aalkjær, C.; Stender, S. Smoking cessation early in pregnancy and birth weight, length, head circumference, and endothelial nitric oxide synthase activity in umbilical and chorionic vessels. An observational study of healthy singleton pregnancies. Circulation 2009, 119, 857-864. [CrossRef] [PubMed]

48. Oliván-Viguera, A.O.; Valero, M.S.; Murillo, M.D.; Wulff, H.; García-Otín, A.L.; Arbonés-Mainar, J.M.; Köhler, R. Novel phenolic inhibitors of small/intermediate-conductance $\mathrm{Ca}^{2+}$-activated $\mathrm{K}^{+}$channels, $\mathrm{KCa} 3.1$ and KCa2.3. PLoS ONE 2013, 8, e58614. [CrossRef]

49. Hessellund, A.; Jeppesen, P.; Aalkjaer, C.; Bek, T. Characterization of vasomotion in porcine retinal arterioles. Acta Ophthalmol. Scand. 2003, 81, 278-282. [CrossRef] [PubMed]

50. Hernanz, R.; Alonso, M.J.; Zibrandtsen, H.; Alvarez, Y.; Salaices, M.; Simonsen, U. Measurements of nitric oxide concentration and hyporeactivity in rat superior mesenteric artery exposed to endotoxin. Cardiovasc. Res. 2004, 62, 202-211. [CrossRef] [PubMed]

(C) 2019 by the authors. Licensee MDPI, Basel, Switzerland. This article is an open access article distributed under the terms and conditions of the Creative Commons Attribution (CC BY) license (http://creativecommons.org/licenses/by/4.0/). 